\title{
Convenient Preparative Method for Lactones from 3-hydroxy Propanoic Acids Using lodine under Solvent-Free Conditions
}

\author{
Yoshio Kasashima ${ }^{1 *}$, Tadasuke Nishida ${ }^{2}$, Hiroshi Fujimoto ${ }^{2}$, Takashi Mino ${ }^{3}$, \\ Masami Sakamoto ${ }^{2}$ and Tsutomu Fujita ${ }^{3}$ \\ ${ }^{1}$ Education center, Faculty of engineering, Chiba Institute of Technology (Shibazono 2-1-1, Narashino-shi, Chiba 275-0023, JAPAN) \\ ${ }^{2}$ Graduate School of Science and Technology, Chiba University (Yayoi-cho 1-33, Inage-ku, Chiba-shi, Chiba 263-8522, JAPAN) \\ ${ }^{3}$ Department of Applied Chemistry and Biotechnology, Faculty of Engineering, Chiba University (Yayoi-cho 1-33, Inage-ku, Chiba-shi, chiba \\ 263-8522, JAPAN)
}

\begin{abstract}
Intramolecular cyclization of 3-hydroxy acids was investigated using iodine as a catalyst under solvent-free conditions. The reaction proceeded to completion in the heterogeneous system. Lactones were obtained by intramolecular cyclization of 3-hydroxy acids. Propella lactone (11-oxatricyclo [4.4.3.0 ${ }^{1,6}$ ]tridecan-12-one) was conveniently synthesized from 3-hydroxy acid ((6-hydroxyspiro[4.5]dec-6yl)acetic acid) in $88 \%$ yield with carbon skeleton rearrangement. Spiro lactones and bicyclic lactones were also obtained from the corresponding 3-hydroxy acids in yields of over $75 \%$. The most suitable reaction conditions were a temperature of $80^{\circ} \mathrm{C}$, a molar ratio of 3-hydroxy acid:iodine $=1: 0.1$, and a time period of $6 \mathrm{~h}$. In addition, terpenic lactones were efficiently synthesized from the corresponding 3-hydroxy acids, derived from $(+)$-camphor, $(-)$-fencone, and $(-)$-pulegone, with skeleton rearrangement. The yield of the solvent-free reaction was as high as that of the corresponding reaction in solution.
\end{abstract}

Key words: iodine, solvent-free, 3-hydroxy acid, lactonization

\section{INTRODUCTION}

It is known that lactones are obtained from hydroxy acids in solution using a strong acid, such as sulfuric acid, as a catalyst ${ }^{1,2)}$. We previously reported efficient intramolecular lactonization of 3-hydroxy acids using iodine as a catalyst and acetonitrile as a solvent ${ }^{3}$. Recently, solvent-free reactions have been investigated from the viewpoint of "green chemistry", and, in particular, iodine has been studied as an efficient catalyst for various reactions under solvent-free conditions ${ }^{4-11}$. In this study, intramolecular lactonization of 3-hydroxy acids was investigated using iodine as a catalyst under solvent-free conditions.

\section{RESULTS AND DISCUSSION}

3 -Hydroxy acids $1 \mathrm{a}$ and $1 \mathrm{~b}$ were prepared by reaction of the corresponding spiro ketone ${ }^{2}$. The reaction of $1 \mathrm{a}$ pro- ceeded to completion in the heterogeneous system. After the reaction, the product was isolated. The spectroscopic data of the product agreed with those of propella- $\gamma$-lactone $2 \mathrm{a}$, which were reported ${ }^{2)}$. Thus, propella- $\gamma$-lactone $2 \mathrm{a}$ was obtained from $1 \mathrm{a}$ by dehydration and carbon skeleton rearrangement. Similarly, propella- $\gamma$-lactone $2 b$ was obtained from 1b. The results are summarized in Table 1. The optimum conditions for the reaction of $1 \mathrm{a}$ were investigated. The material and iodine (molar ratio $=1: 0.1$ ) were put into a sample tube and stirred for $3 \mathrm{~h}$. The reaction was attempted at room temperature (entry 1), but it did not proceed. When the irradiation with ultrasound was carried out (entry 2), the reaction proceeded to a small extent. When the reaction temperature was raised to $80^{\circ} \mathrm{C}$ (entry 4), the yield of $2 a$ improved, reaching $80 \%$. Furthermore, when the reaction time was extended to $6 \mathrm{~h}$ (entry 5 ), the yield was $88 \%$, which is equal to that of the reaction of $1 \mathrm{a}$ in solution. When the molar ratio of iodine was increased to $1: 0.5$ (entry 7), the yield fell to $66 \%$. Under the optimum

* Correspondence to: Yoshio Kasashima, Education center, Faculty of engineering, Chiba Institute of Technology, Shibazono 2-1-1, Narashino-shi, Chiba 275-0023, JAPAN

E-mail: yoshio.kasashima@it-chiba.ac.jp

Accepted December 22, 2006 (received for review November 7, 2006)

Journal of Oleo Science ISSN 1345-8957 print / ISSN 1347-3352 online

http://jos.jstage.jst.go.jp/en/ 
Table 1 Solvent-Free Lactonization of $\mathbf{1 a}$ and $\mathbf{1} \mathbf{b}^{\mathrm{a}}$.

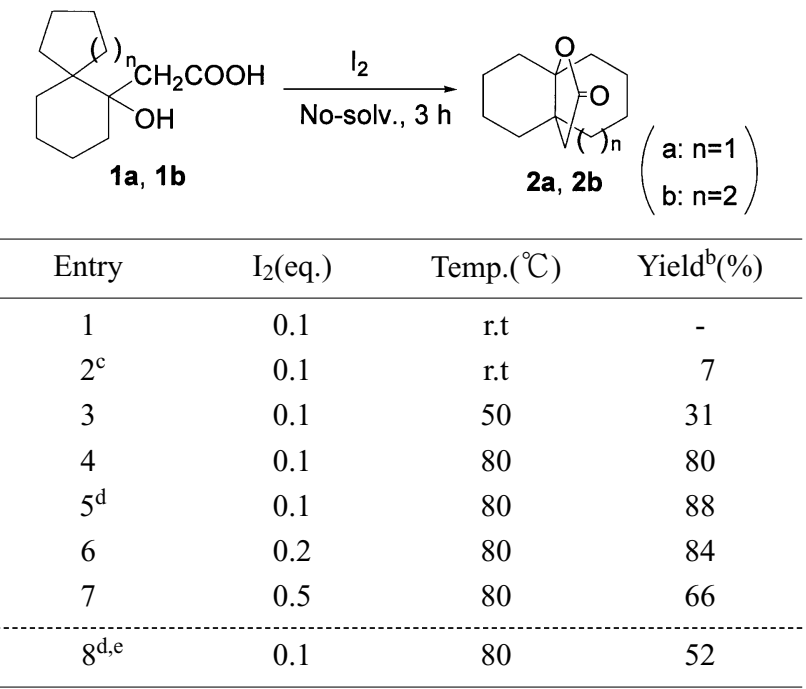

${ }^{\text {a }}$ Conditions: Stirred 3-hydroxy acid $(1.0 \mathrm{mmol})$ with $\mathrm{I}_{2}$.

${ }^{\mathrm{b}}$ Isolated yield.

${ }^{\mathrm{c}}$ Ultrasound was irradiated.

${ }^{\mathrm{d}}$ Stirred for 6 hours.

${ }^{\mathrm{e}}$ Lactonization of $\mathbf{1 b}$

reaction conditions (temperature $80^{\circ} \mathrm{C}$, time $6 \mathrm{~h}$, molar ratio $1: 0.1$ ), the reaction of $1 \mathrm{~b}$ was carried out (entry 8 ). Because the product, propella- $\gamma$-lactone $2 b$, contains an unstable seven-membered ring, the yield was $52 \%$. Thus, in the synthesis of propella- $\gamma$-lactones $2 a$ and $2 b$ from $3-$ hydroxy acids, iodine was shown to be an efficient catalyst in the solvent-free reaction as well as in solution.

A possible reaction mechanism is illustrated in Scheme
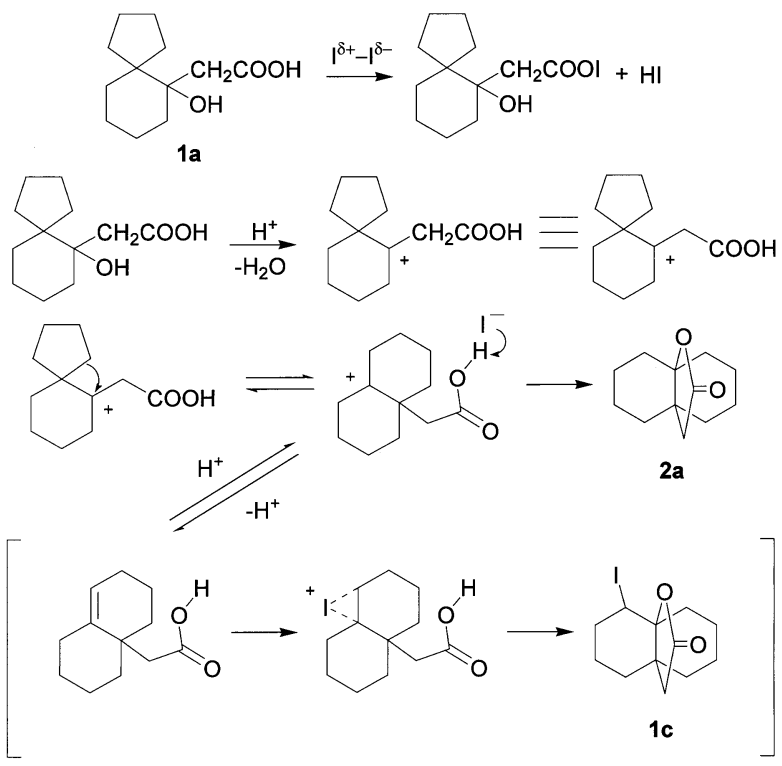

Scheme 1
1. Hydrogen iodide, which is initially formed by the interaction of iodine with the carboxylic acid group, acts as an acidic catalyst to cause the dehydration. An intermediate is formed by skeleton rearrangement, and subsequent nucleophilic attack of the carbocation by the oxygen atom results in the formation of propella- $\gamma$-lactone. In the corresponding solution reaction, small amounts of iodinated propella lactone 1c were formed. However, under solvent-free conditions, formation of $1 \mathrm{c}$ did not occur.

The reaction of 3-hydroxy acid 3a was also examined using iodine under solvent-free conditions. The product was isolated, and the structure was determined based on spectroscopic data as bicyclic lactone 4a. The results under various conditions are shown in Table 2. When the reaction was carried out at $80^{\circ} \mathrm{C}$ for $6 \mathrm{~h}$, the yield of $4 \mathrm{a}$ was over $80 \%$ (entries 5 and 7). It was found that while a molar ratio of starting material : iodine $=1: 0.1$ was the most suitable for the reaction of $1 \mathrm{a}$, a $1: 0.2$ molar ratio was more suitable for the reaction of $3 a$ (entry 7 ). The reaction using $3 \mathrm{~b}$ also produced bicyclic lactone $4 \mathrm{~b}$, but the yield was low (21\%), which was attributed to the formation of an unstable seven-membered ring in the product.

The reaction of 3-hydroxy acid 5a gave spiro lactone 6 a. The results obtained under various conditions are summarized in Table 3. Similarly to the reactions of $1 \mathrm{a}$ and $3 a$, the reaction proceeded smoothly at $80^{\circ} \mathrm{C}$ for $6 \mathrm{~h}$. When the molar ratio of $5 \mathrm{a}$ : iodine was $1: 0.1$, the yield of $6 \mathrm{a}$ was high (76\%; entry 4). From 3-hydroxy acid $5 b$, spiro lactone $6 \mathrm{~b}$ was produced in $80 \%$ yield (entry 7). A possible reaction

Table 2 Solvent-Free Lactonization of $\mathbf{3 a}$ and $\mathbf{3} \mathbf{b}^{\mathrm{a}}$.

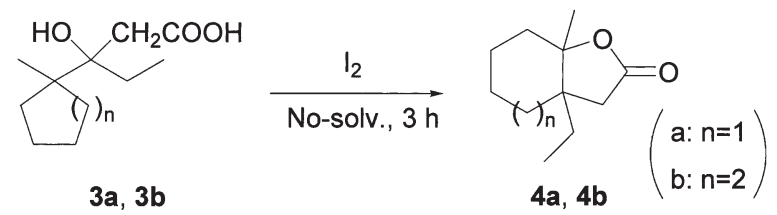

\begin{tabular}{cccc}
\hline Entry & $\mathrm{I}_{2}$ (eq.) & Temp. $\left({ }^{\circ} \mathrm{C}\right)$ & Yield $^{\mathrm{b}}(\%)$ \\
\hline 1 & 0.1 & r.t & - \\
$2^{\mathrm{c}}$ & 0.1 & r.t & 11 \\
3 & 0.1 & 50 & - \\
4 & 0.1 & 80 & 53 \\
$5^{\mathrm{d}}$ & 0.1 & 80 & 82 \\
6 & 0.2 & 80 & 78 \\
$7^{\mathrm{d}}$ & 0.2 & 80 & 88 \\
\hline $8^{\mathrm{d}, \mathrm{e}}$ & 0.1 & 80 & 21 \\
\hline
\end{tabular}

${ }^{\text {a }}$ Conditions: Stirred 3-hydroxy acid $(1.0 \mathrm{mmol})$ with $\mathrm{I}_{2}$.

${ }^{\mathrm{b}}$ Isolated yield.

${ }^{\mathrm{c}}$ Ultrasound was irradiated.

${ }^{\mathrm{d}}$ Stirred for 6 hours.

${ }^{\mathrm{e}}$ Lactonization of $\mathbf{3 b}$. 
Table 3 Solvent-Free Lactonization of $\mathbf{5 a}$ and $\mathbf{5} \mathbf{b}^{\mathrm{a}}$.

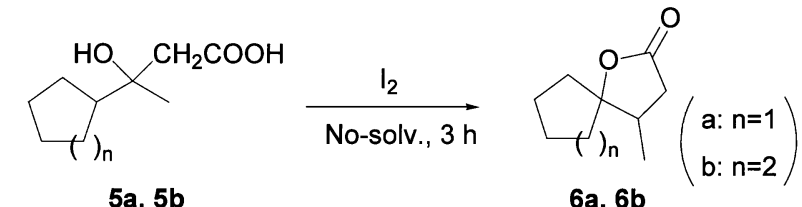

\begin{tabular}{ccccc}
\hline Entry & $\mathrm{n}$ & $\mathrm{I}_{2}(\mathrm{eq})$. & Temp. $\left({ }^{\circ} \mathrm{C}\right)$ & Yield $^{\mathrm{b}}(\%)$ \\
\hline 1 & 1 & 0.1 & r.t & 6 \\
$2^{\mathrm{c}}$ & 1 & 0.1 & r.t & - \\
3 & 1 & 0.1 & 80 & 49 \\
$4^{\mathrm{d}}$ & 1 & 0.1 & 80 & 76 \\
$5^{\mathrm{d}}$ & 1 & 0.2 & 80 & 57 \\
\hdashline 6 & 2 & 0.1 & r.t & - \\
\hdashline $7^{\mathrm{d}}$ & 2 & 0.1 & 80 & 80 \\
$8^{\text {d }}$ & 2 & 0.2 & 80 & 51 \\
\hline
\end{tabular}

${ }^{\text {a }}$ Conditions: Stirred 3-hydroxy acid $(1.0 \mathrm{mmol})$ with $\mathrm{I}_{2}$.

${ }^{\mathrm{b}}$ Isolated yield.

${ }^{\mathrm{c}}$ Ultrasound was irradiated.

${ }^{\mathrm{d}}$ Stirred for 6 hours.

mechanism for the reaction of $5 \mathrm{a}$ is illustrated in Scheme 2. Similarly to the reaction of $1 \mathrm{a}$, hydrogen iodide acts as an acidic catalyst, and a carbocation is generated by dehydration; subsequent hydride shift and attack by the carbonyl oxygen results in formation of the spiro lactone. The preferential formation of the spiro lactone is attributed to the instability of the secondary cation as an intermediate. Thus, the reactions of 3 -hydroxy acids $5 \mathrm{a}$ and $5 \mathrm{~b}$ gave the corresponding spiro lactones.

Bicyclic lactone 8 was obtained from 3-hydroxy acid 7. The results obtained under various conditions are shown in Table 4. Similarly to the other solvent-free lactonizations, the most suitable reaction conditions were found to be a temperature of $80^{\circ} \mathrm{C}$, a molar ratio of $1: 0.1$, and a time of $6 \mathrm{~h}$ (entry 5). The reaction mechanism is considered to be dehydration, followed by the hydride shift, and then for-

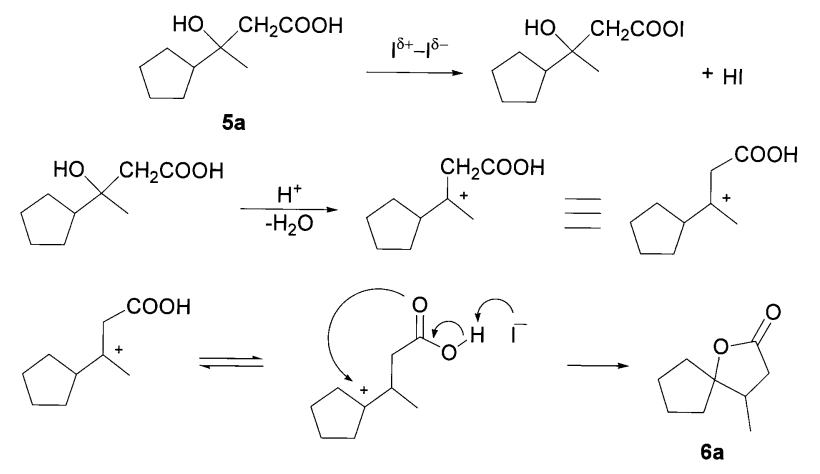

Scheme 2
Table 4 Solvent-Free Lactonization of $\mathbf{7 a}$.

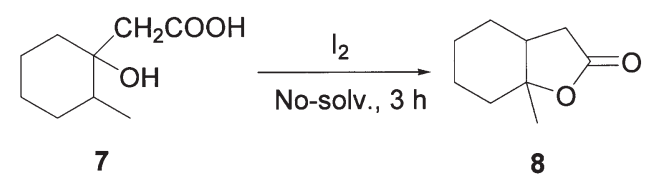

\begin{tabular}{cccc}
\hline Entry & $\mathrm{I}_{2}$ (eq.) & Temp. $\left({ }^{\circ} \mathrm{C}\right)$ & Yield $^{\mathrm{b}}(\%)$ \\
\hline 1 & 0.1 & r.t & - \\
$2^{\mathrm{c}}$ & 0.1 & r.t & - \\
3 & 0.1 & 50 & - \\
4 & 0.1 & 80 & 68 \\
$5^{\mathrm{d}}$ & 0.1 & 80 & 79 \\
6 & 0.2 & 80 & 76 \\
$7^{\mathrm{d}}$ & 0.2 & 80 & 62 \\
8 & 0.5 & 80 & 48 \\
\hline
\end{tabular}

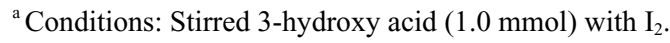

${ }^{\mathrm{b}}$ Isolated yield.

${ }^{\mathrm{c}}$ Ultrasound was irradiated.

${ }^{\mathrm{d}}$ Stirred for 6 hours.

mation of the lactone ring.

A comparison of the method using sulfuric acid, the solution reaction using iodine $\mathrm{e}^{1,3,12)}$, and the solvent-free reaction is illustrated in Table 5. Propella lactone 2a, bicyclic lactones $4 \mathrm{a}$ and 8 , and spiro lactone $6 \mathrm{a}$ were obtained in similar yields in all methods. Thus, the solvent-free reaction is comparable in efficiency and utility with the solution reaction.

Table 5 Comparison between Previous Reports and This Report.

\begin{tabular}{|c|c|c|c|c|}
\hline Entry & Substrates & Products & Conditions & Yield ${ }^{d}(\%)$ \\
\hline 1 & & & $\mathrm{H}_{2} \mathrm{SO}_{4}(0.3$ eq. $) /$ Benzene & $98^{\mathrm{a}}$ \\
\hline 2 & & & $\mathrm{I}_{2}(0.2$ eq. $) /$ Toluene & $87^{\mathrm{b}}$ \\
\hline 3 & 1a & $2 a$ & $\mathrm{I}_{2}(0.1$ eq. $) /$ No-solv. & $88^{\mathrm{c}}$ \\
\hline 4 & $\mathrm{CH}_{2} \mathrm{COOH}$ & & $\mathrm{H}_{2} \mathrm{SO}_{4}(0.3$ eq. $) /$ Benzene & $72^{\mathrm{a}}$ \\
\hline 5 & & & $\mathrm{I}_{2}(0.2$ eq. $) / \mathrm{MeCN}$ & $75^{\mathrm{b}}$ \\
\hline 6 & $3 a$ & & $\mathrm{I}_{2}(0.2 \mathrm{eq}.) / \mathrm{No}-\mathrm{solv}$. & $88^{\mathrm{c}}$ \\
\hline 7 & $\mathrm{CH}_{2} \mathrm{COOH}$ & & $\mathrm{H}_{2} \mathrm{SO}_{4}(0.3$ eq. $) / \mathrm{AcOH}$ & $71^{\mathrm{a}}$ \\
\hline 8 & & & $\mathrm{I}_{2}(0.2$ eq. $) /$ Hexane & $81^{\mathrm{b}}$ \\
\hline 9 & $5 a$ & $6 \mathbf{a}$ & $\mathrm{I}_{2}(0.1$ eq. $) /$ No-solv. & $76^{\mathrm{c}}$ \\
\hline 10 & & & $\mathrm{H}_{2} \mathrm{SO}_{4}(0.3$ eq. $) / \mathrm{AcOH}$ & $88^{\mathrm{a}}$ \\
\hline 11 & & & $\mathrm{I}_{2}(0.2$ eq. $) /$ Hexane & $83^{\mathrm{b}}$ \\
\hline 12 & 7 & 8 & $\mathrm{I}_{2}(0.1$ eq. $) /$ No-solv. & $79^{\mathrm{c}}$ \\
\hline
\end{tabular}

${ }^{\mathrm{a}}$ Refluxed for $8 \mathrm{~h}$.

${ }^{\mathrm{b}}$ Refluxed for $8 \mathrm{~h}$.

${ }^{\mathrm{c}}$ Heated at $80^{\circ} \mathrm{C}$ for $6 \mathrm{~h}$.

${ }^{\mathrm{d}}$ Isolated yield. 
Table 6 Comparison between Previous Reports and This Report.

\begin{tabular}{|c|c|c|c|c|}
\hline Entry & Substrates & Products & Conditions & Yield $^{\mathrm{h}}(\%)$ \\
\hline 1 & & & $\mathrm{AlCl}_{3}$ (0.3eq.)/ $\mathrm{AcOH}$ & $88^{\mathrm{a}}$ \\
\hline 2 & & & $\mathrm{I}_{2}(0.2 \mathrm{eq}.) / \mathrm{MeCN}$ & $83^{\mathrm{b}, \mathrm{d}}$ \\
\hline 3 & $\begin{array}{l}\mathrm{CH}_{2} \mathrm{COOH} \\
9\end{array}$ & & $\mathrm{I}_{2}(0.1$ eq. $) /$ No-solv. & $66^{\mathrm{c}, \mathrm{d}}$ \\
\hline 4 & & & $\mathrm{AlCl}_{3}$ (0.3eq.)/ $\mathrm{AcOH}$ & $88^{\mathrm{a}}$ \\
\hline 5 & COOH & & $\mathrm{I}_{2}(0.2$ eq.) $/ \mathrm{MeCN}$ & $91^{\mathrm{b}, \mathrm{e}}$ \\
\hline 6 & 11 & & $\mathrm{I}_{2}(0.2 \mathrm{eq}.) / \mathrm{No}-\mathrm{solv}$ & $89^{\mathrm{d}, \mathrm{f}}, 86^{\mathrm{g}}$ \\
\hline 7 & & & $\mathrm{H}_{2} \mathrm{SO}_{4}(0.3$ eq. $) /$ Benzene & $94^{\mathrm{a}}$ \\
\hline 8 & & & $\mathrm{I}_{2}(0.2$ eq. $) / \mathrm{MeCN}$ & $88^{\mathrm{b}, \mathrm{e}}$ \\
\hline 9 & & & $\mathrm{I}_{2}(0.1$ eq. $) /$ No-solv. & $88^{\mathrm{c}, \mathrm{f}}$ \\
\hline
\end{tabular}

${ }^{\text {a }}$ Refluxed for $8 \mathrm{~h}$.

${ }^{\mathrm{b}}$ Stirred for $3 \mathrm{~h}$.

${ }^{\mathrm{c}}$ Stirred for $6 \mathrm{~h}$.

${ }^{\mathrm{d}}$ R.t..

${ }^{\mathrm{e}}$ Reflux.

${ }^{\mathrm{f}} 80^{\circ} \mathrm{C}$.

${ }^{\mathrm{g}}$ Quench was omitted.

${ }^{\mathrm{h}}$ Isolated yield.

This method was also used in the lactonization of terpenic 3-hydroxy acids derived from $(+)$-camphor 9, (-)fencone 11 , and $(-)$-pulegone 13 . The results are summarized in Table 6. The yield of lactone 10 from 3-hydroxy acid 9 was somewhat low under solvent-free conditions, but the other lactones were obtained in high yields of over $85 \%$. The mechanisms of the reactions of 9 and 11 are thought to involve a Wagner-Meerwein- type rearrangement $t^{3)}$. The reaction of 13 probably proceeds via dehydration followed by the formation of a stable cation.

It is concluded that the reaction of 3-hydroxy acids using iodine as a catalyst under solvent-free conditions proceeds smoothly to give the corresponding lactones, and that the yields obtained by this method are as high as those obtained in the corresponding solution reactions.

\section{EXPERIMENTAL}

1. General

NMR spectra were obtained using a 400 or $500 \mathrm{MHz}$ FTNMR spectrometer (JEOL JNM-LA-400 or JNM-LA-500) with an internal standard. IR spectra were recorded on a JASCO FT/IR-230 spectrometer. Mass spectra were recorded on a JEOL JMS-HX110A and JEOL JMS-AX500.

\section{Materials}

3-Hydroxy acids (6-hydroxyspiro[4.5]dec-6-yl)acetic acid $1 \mathrm{a}$, (1-hydroxyspiro[5.5]undec-1-yl)acetic acid 1b,

3-hydroxy-3-(1-methylcyclopentyl)pentanoic acid 3a,

3-hydroxy-3-(1-methylcyclohexyl)pentanoic acid 3b,

3-cyclopentyl-3-hydroxybutyric acid 5a,

3-cyclohexyl-3-hydroxybutyric acid 5b,

(1- hydroxy-2-methylcyclohexyl)acetic acid 7,

(2- hydroxy-1,7,7-trimethylbicyclo[2.2.1]hept-2-yl)acetic acid 9 ,

(3- hydroxy-1,3,3-trimethylbicyclo[2.2.1]hept-2-yl)acetic acid 11 , and

(1-hydroxy-2-isopropylidene-5-methylcyclohexyl)-acetic acid 13 ,

were prepared by reaction of the corresponding ketones with acetic acid using lithium naphthalenide, as previously reported ${ }^{3)}$.

\section{Lactonization}

A typical procedure is as follows:

In a sample tube were placed $212 \mathrm{mg}(1.0 \mathrm{mmol})$ of $1 \mathrm{a}$ and $25 \mathrm{mg}(0.1 \mathrm{mmol})$ of iodine, and the mixture was stirred at $80^{\circ} \mathrm{C}$ for $6 \mathrm{~h}$. A $5 \%$ aqueous solution of sodium thiosulfate was added to the reaction mixture in order to remove iodine, and the mixture was then extracted with diisopropyl ether three times. The organic layer was washed with water, dried with anhydrous sodium sulfate, and evaporated. The product was purified by column chromatography. A total of $170 \mathrm{mg}$ ( $0.88 \mathrm{mmol}$; 88\% yield) of 11-oxatricyclo[4.4.3.0 $\left.0^{1,6}\right]$ tridecan-12-one 2a was obtained.

The spectroscopic data of the product agreed with those of $2 \mathrm{a}^{2)}$.

The spectroscopic data of the product from $1 \mathrm{~b}$ agreed with those of 12-Oxatricyclo[5.4.3.0 $\left.0^{1,7}\right]$ tetradecan-13-one $e^{2)} 2 b$. Yield, 52\%.

3a-Ethyl-7a-methylhexahydrobenzofuran-2-one 4a; colorless liquid.

${ }^{1} \mathrm{H}-\mathrm{NMR}\left(\boldsymbol{\delta}, \mathrm{CDCl}_{3}\right): 0.89\left(3 \mathrm{H}, \mathrm{t}, \boldsymbol{J}=7.5 \mathrm{~Hz}, \mathrm{CH}_{3} \mathrm{CH}_{2}\right), 1.28(3 \mathrm{H}$, s, $\left.\mathrm{CH}_{3}\right), 1.34-1.92\left(10 \mathrm{H}, \mathrm{m}, \mathrm{CH}_{2} \mathrm{X} 4\right.$ and $\left.\mathrm{CH}_{3} \mathrm{CH}_{2}\right), 2.36(2 \mathrm{H}, \mathrm{q}$, $\left.J_{\mathrm{AB}}=16.9 \mathrm{~Hz}, \mathrm{CH}_{2} \mathrm{C}=\mathrm{O}\right)$

${ }^{13} \mathrm{C}-\mathrm{NMR}\left(\boldsymbol{\delta}, \mathrm{CDCl}_{3}\right): 9.7,21.4,22.1,23.1,25.4,30.3,34.6$, 41.2, 44.6, 88.3, 177.0

IR (neat, $\left.\mathrm{cm}^{-1}\right): 1770(\mathrm{C}=\mathrm{O})$

HRMS(FAB) calcd for $\mathrm{C}_{11} \mathrm{H}_{19} \mathrm{O}_{2}[\mathrm{M}+\mathrm{H}]^{+}:$183.1385; found: $\mathrm{m} / z 183.1385$.

Yield, 88\%.

3a-Ethyl-8a-methyloctahydrocyclohepta[b]furan-2-one 4b; colorless liquid.

${ }^{1} \mathrm{H}-\mathrm{NMR}\left(\boldsymbol{\delta}, \mathrm{CDCl}_{3}\right): 0.91\left(3 \mathrm{H}, \mathrm{t}, J=7.5 \mathrm{~Hz}, \mathrm{CH}_{3} \mathrm{CH}_{2}\right), 1.01(3 \mathrm{H}$, s, $\left.\mathrm{CH}_{3}\right), 1.12-1.90\left(12 \mathrm{H}, \mathrm{m}, \mathrm{CH}_{2} \mathrm{X} 5\right.$ and $\left.\mathrm{CH}_{3} \mathrm{CH}_{2}\right), 2.35(2 \mathrm{H}, \mathrm{q}$, $\left.J_{\mathrm{AB}}=17.1 \mathrm{~Hz}, \mathrm{CH}_{2} \mathrm{C}=\mathrm{O}\right)$

${ }^{13} \mathrm{C}-\mathrm{NMR}\left(\delta, \mathrm{CDCl}_{3}\right): 9.8,20.1,22.4,22.8,25.7,28.4,31.5$, $31.7,42.3,45.1,90.3,176.5$ 
IR (neat, $\left.\mathrm{cm}^{-1}\right): 1770(\mathrm{C}=\mathrm{O})$

HRMS(FAB) calcd for $\mathrm{C}_{12} \mathrm{H}_{21} \mathrm{O}_{2}[\mathrm{M}+\mathrm{H}]^{+}:$197.1542; found: $\mathrm{m} / z 197.1541$.

Yield, 22\%.

The spectroscopic data of the product from $5 \mathrm{a}$ agreed with those of 4-Methyl-1-oxaspiro[4.4]nonan-2-one ${ }^{13)} 6$ a. Yield, $76 \%$.

4-Methyl-1-oxaspiro[4.5]decan-2-one 6b; colorless liquid.

${ }^{1} \mathrm{H}-\mathrm{NMR}\left(\boldsymbol{\delta}, \mathrm{CDCl}_{3}\right): 1.05$ (3H, d, $\left.J=6.5 \mathrm{~Hz}, \mathrm{CH}_{3} \mathrm{CH}\right), 1.21-1.84$ $\left(10 \mathrm{H}, \mathrm{m}, \mathrm{CH}_{2} \mathrm{X} 5\right), 2.25(1 \mathrm{H}, \mathrm{dd}, J=20.6,9.2 \mathrm{~Hz}, \mathrm{CHC}=\mathrm{O})$, 2.19-2.32 (1H, m, $\left.\mathrm{CH}_{3} \mathrm{CH}\right), 2.68(1 \mathrm{H}, \mathrm{dd}, J=20.6,11.6 \mathrm{~Hz}$, $\mathrm{CHC}=\mathrm{O})$

${ }^{13} \mathrm{C}-\mathrm{NMR}\left(\boldsymbol{\delta}, \mathrm{CDCl}_{3}\right): 14.8,22.1,23.0,25.7,31.1,36.5,37.0$, $39.8,88.6,176.6$

IR (neat, $\left.\mathrm{cm}^{-1}\right): 1770(\mathrm{C}=\mathrm{O})$

HRMS(FAB) calcd for $\mathrm{C}_{10} \mathrm{H}_{17} \mathrm{O}_{2}[\mathrm{M}+\mathrm{H}]^{+}:$: 169.1229; found: $\mathrm{m} / z 169.1238$.

Yield, 80\%.

The spectroscopic data of the product from 7 agreed with those of cis-6-Methyl-7-oxabicyclo[4.3.0]nonan-8-one ${ }^{3)} 8$. Yield, 79\%.

The spectroscopic data of the product from 9 agreed with those of 5,6,6-Trimethyl-4-oxatricyclo[5.2.1.1.,5]decan-3one $^{3)} 10$. Yield, $66 \%$.

The spectroscopic data of the product from 11 agreed with those of 5,10,10-Trimethyl-4-oxatricyclo[5.2.1.0 $\left.{ }^{1,5}\right]$ decan-3one $^{3)} 12$. Yield, $89 \%$.

The spectroscopic data of the product from 13 agreed with those of 2,2,8-Trimethyl-3-oxabicyclo[4.4.0]-dec-1(6)-ene-4one $^{3)} 14$. Yield, $88 \%$.

\section{References}

1. Fujita, T.; Watanabe, S.; Tohtani, M.; Suga, K. A convenient preparation of $\gamma$-lactones and dialkyltetrahydrofurans from the reaction of fatty acids with epoxides using lithium naphthalenide. J. Am. Oil Chem. Soc. 61, 1604-1606 (1984).

2. Fujita, T.; Watanabe, S.; Suga, K.; Y. Higuchi, Y.; Sotoguchi, T. A convenient preparative method of
[m.n.3]Propella- $\gamma$-lactones. J. Org. Chem. 49, 1975-1977 (1984).

3. Fujita, T.; Hanyu, N.; Mino, T.; Sakamoto, M. Iodine mediated lactonization of terpenic 3-hydroxy acids. Synthesis, 1846-1850 (2001).

4. Matsumoto, S.; Kumazawa, K.; Ogura, K. Novel solvent-free reactions with iodine: Solid-solid and solidvapor reactions of 1-Aryl-4-(methylthio)-2-( $p$-Tolylsulfonyl)-1,3-butadienes. Bull. Chem. Soc. Jpn. 76, 21792182 (2003).

5. Phukan, P. Iodine as an extremely powerful catalyst for the acetylation of alcohols under solvent-free conditions. Tetrahedron Lett. 45, 4785-4787 (2004).

6. Chu, C-M.; Gao, S.; Sastry, M.N.V.; Yao, C-F. Iodine catalyzed conjugate addition of mercaptans to $\alpha, \beta$-unsaturated carboxylic acids under solvent-free condition. Tetrahedron Lett. 46, 4971-4974 (2005).

7. Gao, S.; Tzeng, T.; Sastry, M. N. V. ; Chu, C-M.; Liu, JT.; Lin, C.; Yao, C-F. Iodine catalyzed conjugate addition of mercaptanes to $\alpha, \beta$-unsaturated carboxylic acids under solvent-free condition. Tetrahedron Lett. 47, 1889-1893 (2006).

8. Varala, R.; Sreelatha, A.; Adapa, S.R. Molecular iodinecatalyzed facile procedure for N-boc protection of amines. J. Org. Chem. 71, 8283-8286 (2006).

9. Ahmed, N.; Lier, J.E.van Molecular iodine in isopropenyl acetate (IPA): A highly efficient catalystfro the acetylation of alcohols, amines, and phenols under solvent-free conditions. Tetrahedron Lett. 47, 53455349 (2006).

10. Pasha, M.A.; Jayashankara, V.P. Efficient synthesis of N,N'-disubstituted ureas/thioureas catalyzed by iodine. Synthetic Commun. 36, 1787-1793 (2006).

11. Bez, G.; Baruah, N. Microwave-mediated efficient protection of carbonyl compounds as 1,3-oxathiolanes in the presence of iodine under solvent free conditions. Chem. Lett. 35, 542-543 (2006).

12. Watanabe, S.; Fujita, T.; Sakamoto, M.; Furuuchi, M.; Hanyu, N. Synthesis of various lactones from terpenoid cyclic ketones, 41th Symposium on the Chemistry of Terpenes, Essential Oils and Aromatics, 202-204 (1997).

13. Bunce, R.A.; Drumright, R.; Taylor, V.L. Amberlyst-15 promoted synthesis of fused and spiro $\gamma$-butyrolactones from $\beta$-hydroxy esters. Synthetic Commun. 19, 24232430 (1989). 